\title{
Violência, silêncio e revolta velada nas leituras de Safo (fr. 31 Voigt)
}

\author{
Sara Camila Barbosa dos Anjos' (iD 0000-0001-7574-7289 \\ Rafael Guimaraes Tavares da Silva ${ }^{2}$ (iD) 0000-0002-8985-8315 \\ 'Universidade Federal de Minas Gerais, Faculdade de Letras, Belo Horizonte, MG, \\ Brasil. 31270-010 \\ 2Universidade Federal de Minas Gerais, Faculdade de Letras, Pós-Graduação em \\ Literatura, Belo Horizonte, MG, Brasil. 31270-010
}

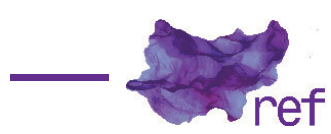

Resumo: A história da recepção dos poemas de Safo varia gradualmente, ao ritmo das mudanças na própria mentalidade de seus leitores, de modo que acompanhar diacronicamente essa variação é evidenciar o desenvolvimento do imaginário social com relação a muitas das questões complexas trazidas por sua poesia. A posição social da mulher, por exemplo, ou aspectos do homoerotismo assuntos bastante imbricados em Safo - prestam-se de modo frequente como material para essas leituras, partindo de algumas das perspectivas vigentes num dado período a fim de criar e reforçar discursos de poder. O famoso fragmento 31 Voigt de Safo é um caso emblemático dessa multiplicidade de leituras. Nosso intuito é partir dele para tecer considerações e esclarecimentos sobre algumas facetas da obra de Safo encobertas por séculos de violência, silêncio e revolta velada.

Palavras-chave: Safo de Lesbos; estética da recepção; estudos de gênero; estudos clássicos; estudos feministas.

\section{Violence, Silence and Veiled Revolt in the Readings of Sappho (fr. 31 Voigt)}

Abstract: Sappho's poems received a varied reception throughout history, accordingly to the changes in the mentality of its readers. To follow diachronically this variation is to evidence some developments in the social imaginary about many complex questions evoked by her poetry. The social position of women, for example, or certain aspects of homoeroticism - subjects profoundly imbricated in Sappho - are frequently used as material for these readings, departing from some of the current perspectives in one period, in order to create and reinforce certain discourses of power. The famous fragment 31 Voigt of Sappho is an emblematic case of this multiplicity of interpretations. Our aim here is to depart from it to weave a series of considerations and elucidations about some of Sappho's facets hidden by centuries of violence, silence and veiled revolt.

Keywords: Sappho of Lesbos; Reception Theory; Gender Studies; Classical Studies; Feminist Studies.

\section{Violencia, silencio y revuelta velada en las lecturas de Safo (fr. 31 Voigt)}

Resumen: Los poemas de Safo recibieron una acogida variada a lo largo de la historia, de acuerdo con los cambios en la mentalidad de sus lectores. Seguir diacrónicamente esta variación es evidenciar algunos desarrollos en el imaginario social sobre muchas cuestiones complejas evocadas por su poesía. La posición social de la mujer, por ejemplo, o ciertos aspectos del homoerotismo sujetos profundamente imbricados en Safo - se utilizan frecuentemente como material para estas lecturas, partiendo de algunas de las perspectivas actuales en un período, con el fin de crear y reforzar ciertos discursos de poder. El famoso fragmento 31 Voigt de Safo es un caso emblemático de esta multiplicidad de interpretaciones. Nuestro objetivo aquí es apartarnos de él para tejer una serie de consideraciones y elucidaciones sobre algunas de las facetas de Safo ocultas por siglos de violencia, silencio y revuelta velada.

Palabras Ilave: Safo de Lesbos; teoría de la recepción; estudios de género; estudios clásicos; estudios feministas. 
Safo de Lesbos é uma poeta grega antiga, cuja vida se desenrolou entre os anos de 630 e 580 a.C., com um destino excepcional para uma mulher do contexto histórico em que viveu: compôs poemas que se tornaram incontornáveis no âmbito da tradição literária ocidental, figurando como um dos expoentes da poesia grega e de um de seus gêneros mais importantes, a mélica (habitualmente chamada de lírica). Embora seja o único nome feminino no conjunto de poetas cuja obra nos chegou da Grécia arcaica (ca. 800-480 a.C.), e muitas anedotas sobre sua vida possam ser colhidas em obras posteriores, pouquíssimas são as informações seguras de cunho biográfico acerca dela - como costuma acontecer com a maioria dos poetas do período arcaico.

A helenista brasileira Giuliana Ragusa (2005) enfatiza em suas obras o cuidado necessário no tratamento da poesia grega antiga, sobretudo no que tange às possíveis biografias e anedotas acerca dos poetas. No caso específico de Safo, ela chama atenção para o fato de que "cada época criou a sua imagem da poeta com maior liberdade do que normalmente aconteceria se houvesse dados mais seguros sobre sua existência histórica" (RAGUSA, 2005, p. 32). Assim sendo, convém abordar o corpus poético atribuído a essa poeta com bastante atenção aos próprios textos que nos chegaram, pois eles constituem os dados mais seguros para uma compreensão daquilo que se encontra em jogo nas discussões em torno de Safo.

A história da recepção desses poemas variou radicalmente, ao ritmo das mudanças na própria mentalidade de seus leitores e suas leitoras, de modo que acompanhar diacronicamente essa variação é evidenciar o desenvolvimento do imaginário social com relação a muitas das questões complexas trazidas por sua poesia. A posição social da mulher, por exemplo, ou alguns aspectos do homoerotismo - assuntos profundamente imbricados em Safo - prestam-se de modo frequente como material para essas leituras, partindo de algumas das perspectivas vigentes num dado período a fim de criar e reforçar certos discursos de poder.

Antes de entrarmos no debate de uma questão específica da recepção conferida à poesia de Safo, convém ter em mente o interesse que pode haver em estudos desse tipo de material ainda hoje. Para recorrer aqui às palavras de Virginia Woolf (2015) sobre a constituição gradual de uma tradição de escrita por mulheres e a importância de uma tomada de consciência acerca dela, tal como ela propõe em 1929, em seu livro antológico A room of one's own [Um teto todo seu], lembramos:

[S]e você considerar qualquer grande figura do passado, como Safo, como a senhora Murasaki, como Emily Brontë, você descobrirá que ela é uma herdeira, assim como uma criadora, e passou a existir porque mulheres vieram a adquirir o hábito de escrever naturalmente [...] (WOOLF, 2015, p. 79, tradução nossa).

Nesse sentido, o conhecimento dessa tradição e da história de suas interpretações é fundamental para o desenvolvimento futuro dessa mesma tradição, bem como para a tomada de consciência acerca das inúmeras questões relacionadas a ela, entre obstáculos, conquistas e desafios. O famoso fr. 31 de Safo é um caso emblemático da multiplicidade de interpretações a que um texto pode ser submetido ao longo da história. Esse poema sobreviveu graças à admiração do autor do tratado antigo Do sublime', uma vez que ele o cita em sua obra como um exemplo

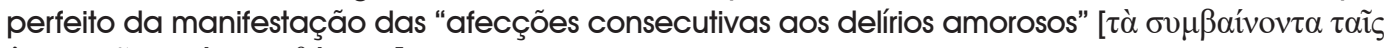
$\dot{\varepsilon} \rho \omega \tau 1 \kappa \alpha i ٓ \varsigma ~ \mu \alpha v i ́ a 1 \varsigma \pi \alpha \theta \eta ́ n \mu \alpha \tau \alpha]$. Segundo essa passagem do tratado, a poeta demonstraria em seus versos sua capacidade "de escolher e de ligar o que há de mais agudo e de mais intenso nessas

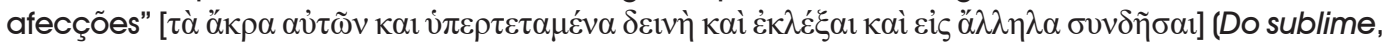
10.1). Embora a própria fonte antiga desse poema já proponha a compreensão de que ele seria uma manifestação dos efeitos da 'paixão erótica' - ou melhor, de um "concurso de paixões"

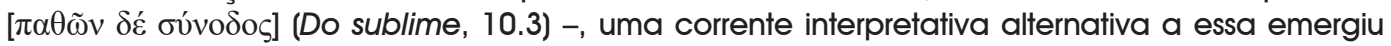
pouco a pouco na história de sua recepção, sugerindo o papel central que o 'ciúme' teria como fonte daquilo que é descrito ao longo desses versos. É fato conhecido que Catulo, ainda no século I a.C., retomou esse poema de Safo em latim; em sua versão, uma persona poética masculina surge sob os fortes efeitos de um ataque de ciúmes com relação à mulher amada, devido à presença de um rival. Sob a influência dessa interpretação latina - e eminentemente masculina, diga-se de passagem -, uma tradição interpretativa do fr. 31 de Safo como um poema sobre um ataque de ciúmes se consolidou pouco a pouco, chegando até os dias de hoje.

As duas principais correntes interpretativas desses versos encontram o seu ponto de inflexão num ínfimo pronome relativo - o pronome tó [isso], do grego antigo, presente no quinto verso do poema -, o qual, com seu valor dêitico, parece ter uma referência aberta o bastante para

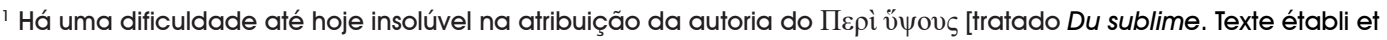
traduit par Henri Lebègue. Paris: Les Belles Lettres, 1997]. Em 1809, um manuscrito da Biblioteca Vaticana (Vaticanus 285) revelou um pormenor: separando os nomes Dionísio e Longino, uma conjunção disjuntiva - $\Delta$ lovvóíov $\grave{\eta}$

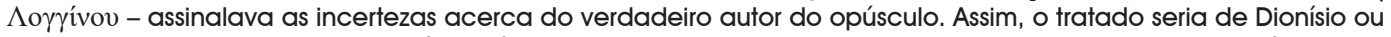
de Longino, o que significa que, já no séc. X d.C., se desconhecia a identidade do escritor e se atribuía a obra a um dos grandes críticos literários do período imperial (LONGINO. Do sublime. Tradução de Filomena Hirata. São Paulo: Martins Fontes, 1996). 
comportar dois referentes diversos igualmente possíveis. Vejamos inicialmente o poema na íntegra para que possamos delinear com maior precisão os principais argumentos desta discussão:

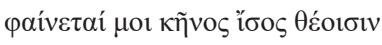

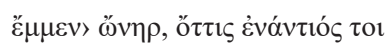

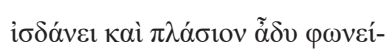

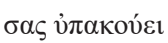

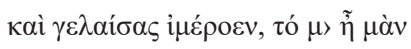

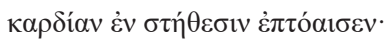

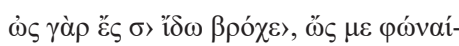

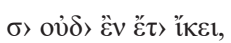

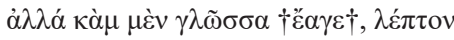

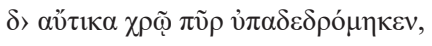

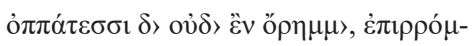

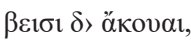

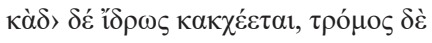

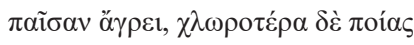

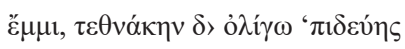

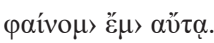

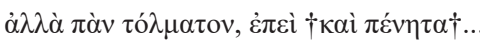

(SAFO, fr. 31 Voigt).

Em nossa tradução - sem fins poéticos, mas com pretensões acadêmicas -, proposta a fim de elucidar as questões a serem debatidas na sequência de nossa exposição, temos:

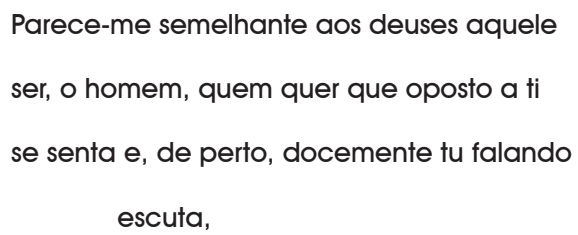


e com meus olhos nada vejo, e

zumbem meus ouvidos

e água escorre, e um tremor

de todo me toma, e mais verde que a relva

estou, e faltosa de pouco para morrer

pareço eu mesma.

Mas tudo é suportável, pois mesmo um pobre...

A primeira dessas correntes interpretativas - cuja aceitação é bem menor hoje em dia do que há um século, embora tenha tido uma quantidade razoável de adeptos ao longo de toda a história - é a que vê no pronome tó [isso] a intimidade com que um homem real - ainda que ele seja ísos théoisin [semelhante aos deuses] - escuta a fala doce e o riso prazenteiro da garota amada pela persona poética feminina (as concordâncias da primeira pessoa com adjetivos e particípios no feminino indicam-nos claramente que se trata de uma persona feminina). Esse fato real seria a fonte de um ataque de ciúmes cujo quadro clínico - descrito nas estrofes seguintes daria detalhes hiperbólicos justamente para sugerir a hipérbole dos sentimentos dessa persona.

A interpretação do fr. 31 mais aceita hoje em dia (embora já fosse comum desde a própria antiguidade) sugere que o pronome tó [isso] estaria se referindo ao pensamento de que, quando a persona por ventura se encontrasse na mesma posição daquele homem, ou seja, próxima da doce fala e do riso prazenteiro da garota amada, não conseguiria manter a mesma imperturbabilidade que ele - evocado justamente com um epíteto homérico, ísos théoisin, tal como anota William $\mathrm{H}$. Race (1983) -, mas padeceria conforme a descrição patológica das estrofes seguintes deixa ver. A figura 'daquele homem' na estrofe inicial, portanto, desempenharia um papel de contraste com relação ao posicionamento da própria persona do poema (RACE, 1983).

Para simplificar, podemos compreender as leituras que se orientam pela primeira interpretação como relacionadas ao 'ciúme' da persona poética e as que se orientam pela segunda, como relacionadas à sua 'paixão'. Tal como afirmamos anteriormente, a ideia do ciúme tem encontrado alguma resistência na bibliografia recente sobre o assunto, embora ainda conte com alguns defensores (como mencionaremos na sequência de nosso argumento).

Exemplos dessa interpretação poderiam ser encontrados em autores franceses do século XVI, tal como bem demonstrado pelo artigo de Robert Aulotte (1958). Esse mesmo tipo de interpretação - complementado pela sugestão de caráter biografizante, segundo a qual esse poema seria um epitalâmio, ou seja, uma composição para execução pública num contexto matrimonial - foi defendida por estudiosos com o renome de Ulrich von Wilamowitz-Moellendorff (1913) e de Bruno Snell (2012) (orig. de 1946).

À guisa de exemplo da manifestação moderna dessa corrente interpretativa, citemos as palavras deste último:

O poema é um epitalâmio em honra de uma jovem do círculo de Safo e começa pela tradicional louvação do homem que desposa a garota. Mas essas núpcias separam Safo da amada. O amor, que, nos versos citados anteriormente [fr. 16 Voigt], Safo apresentara como a instância suprema na decisão do que fosse o belo, é, tanto neste quanto naquele caso, o amor infeliz, ali pela amada distante, aqui pela que parte. E assim como Arquíloco dizia sentir que as forças o abandonavam, deixando-o sem vida, assim também Safo descreve de modo apavorante o desfalecimento dos sentidos e da energia vital e a rápida chegada da morte (SNELL, 2012, p. 63-64).

Ambos os helenistas alemães compartilham a ideia de que esse poema tem características de um Hochzeitslied [canção matrimonial, epitalâmio]. Tal sugestão tenta oferecer respostas para o papel do 'homem' na primeira estrofe do poema, ainda que incorrendo no risco de supervalorizar uma figura de todo ausente nas outras estrofes. Para propor algo assim, esses analistas recorrem a argumentos de ordem lexical, mas o tom patológico com que é descrita a paixão da persona pela pretensa noiva dificilmente estaria afinado ao contexto de performance correspondente a um casamento (Thomas MCEVILLEY, 1978). Além disso, a ausência de palavras que remetam diretamente a uma situação de himeneu é por demais evidente para que essa leitura possa ser levada a sério ainda hoje, quando certos pressupostos biográficos - enganosos, é preciso dizer - são deixados de lado pelos intérpretes da poesia grega arcaica. 
Afirmando levar em conta essas dificuldades, McEvilley (1978) tentou resguardar em parte a interpretação do poema como uma espécie de epitalâmio, propondo, contudo, que ele misturaria convenções de gêneros poéticos diferentes (mistura essa que teria ocasionado a confusão dos estudiosos anteriores da questão). Em sua opinião, as interpretações tradicionais seriam insuficientes quando defendiam que aquele poema seria um epitalâmio tout court, bem como quando negavam que contivesse algo desse aspecto matrimonial:

É preciso lembrar que estamos lidando com uma poeta sutil que caracteristicamente mistura as convenções de diferentes gêneros (especialmente coral e monódico) e que atinge, através dessa mistura, efeitos em vários níveis envolvendo irônicos jogos internos entre os temas do objetivo e do subjetivo, do público e do privado, do externo e do interno, do histórico e do poético (MCEVILLEY, 1978, p. 12, tradução nossa).

Os argumentos, contudo, para explicar o 'hibridismo genérico' desse poema denunciam imediatamente o romantismo da concepção poética projetada por esse intérprete sobre a poesia mélica do período arcaico, como transparece no seguinte trecho:

Ela parece ser a primeira dos poetas a deixar um registro do que se tornara desde então uma situação familiar: o poeta como uma alma sensível sofrendo sentimentos de frustração e alienação a partir de problemas em relacionar o seu trabalho com realidades sociais convencionais. Desnecessário dizer, nesse caso a situação era agravada pela homossexualidade de Safo. Que ela, não podendo participar da felicidade de se casar com uma dessas garotas, tivesse que cantar louvores daqueles que se casavam com elas, isso deve ter parecido um amargo paradoxo, com efeito. E no fr. 31, talvez pela primeira vez, ela permitiu que esse paradoxo amargo emergisse na superfície e fosse claramente expresso (MCEVILLEY, 1978, p. 15, tradução nossa).

Somemos ao anacronismo dessa abordagem romântica a ausência no poema de vocábulos que remetam diretamente a um contexto matrimonial (RACE, 1983), e a fraqueza de tal interpretação revela-se inteiramente. Ou seja, a tentativa de ler esses versos como um testemunho da expressão de certa subjetividade que, por meio da subversão do gênero epitalâmico, faria uma crítica social à situação do poeta, além de ignorar a ausência de muitas das características básicas de tal gênero poético, impõe categorias modernas ao juízo sobre um período muito recuado no tempo.

Como se vê, não podemos estar de acordo com a interpretação segundo a qual o ciúme seria a causa daquilo que está descrito entre os sintomas patológicos nas estrofes 2,3 e 4. Já a corrente interpretativa que propõe a paixão como razão por trás daquele quadro clínico descrito hiperbolicamente pela persona poética vê no pronome relativo tó [isso] a retomada de traços específicos da beleza sedutora da garota (Miroslav MARCOVICH, 1972). Um exemplo dessa forma de compreender o poema remonta ao próprio autor do tratado Do sublime (como vimos anteriormente), mas já pode ser encontrada entre autores modernos, como na obra de uma erudita do século XVI. Anne Le Fèvre - mais conhecida por seu nome de casada, Madame Dacier (1699) -, propõe em sua edição bilíngue dos poemas de Anacreonte e Safo as seguintes considerações, baseando-se no trecho já citado do tratado Do sublime:

Com efeito, Safo, para marcar a violência de seu amor, escolhe tão bem os acidentes que ocorrem verdadeiramente nessa paixão que, de todas as coisas que ela reúne - a alma, o corpo, a audição, a voz, a vista, a cor -, ela faz como muitas pessoas que estão a ponto de morrer. Ela parece ao mesmo tempo tomada de paixões contrárias, ela gela, ela arde, ela extravaga, ela está no controle dos sentidos. E isso para fazer aparecer não apenas uma só paixão, mas todas as paixões ao mesmo tempo, uma reunião geral de todas as paixões (DACIER, 1699, p. 260, tradução nossa).

Em texto publicado num volume recente sobre a história de mulheres envolvidas no campo dos Estudos Clássicos, Jacqueline Fabre-Serris (2016) analisa as traduções e observações tanto de Madame Dacier quanto aquelas que Renée Vivien (1903) viria a adotar séculos mais tarde, em publicação de 1903, seguindo nos passos de sua antecessora. Como bem colocado pela estudiosa, ambas se identificam com Safo como mulher apaixonada e poeta, buscando nela o suporte de que precisam para enfrentar a sociedade de suas épocas:

Anne Le Fèvre, para mulheres tendo sucesso em competir com homens; Renée Vivien, para mulheres amando mulheres e escrevendo sobre seus amores. Separadas por séculos, ambas buscaram o mesmo público: mulheres com as quais compartilhar seus gostos e conquistas, idealmente uma comunidade de amigas [...] (FABRE-SERRIS, 2016, p. 102, tradução nossa).

Ao seguir nessa mesma linha - pautada por uma preocupação com o que é efetivamente proposto pela persona poética de Safo a partir da paixão com que se expressa nesse poema -, temos a consolidação cada vez maior dessa vertente interpretativa. Aprofundamento dessa tendência - ainda que sua radicalidade eventualmente coloque em risco até as bases 
históricas mais fundamentais - é a que se opera em leituras contemporâneas interessadas em questões identitárias, como aquelas relativas a sexualidade e gênero. Um exemplo desse tipo de leitura é avançado pela estudiosa Judith P. Hallett (1993), cujo engajamento é manifestamente expresso num texto como Feminist Theory, Historical Periods, Literary Canons, and the Study of Greco-Roman Antiquity [Teoria feminista, períodos históricos, cânones literários e o estudo da antiguidade greco-romana], publicado em 1993. Com relação a Safo, esse aspecto de seu trabalho acadêmico se dá a ver em palavras como as seguintes:

Em todo caso, quando escreve na primeira pessoa, Safo não escamoteia uma 'paixão amorosa' com relação a outras mulheres e profere fortes sentimentos homossexuais. No fragmento 31, por exemplo, Safo representa a si mesma enquanto responde aos charmes de uma amiga com violentas reações físicas (HALLETT, 1996, p. 132, tradução nossa).

Em primeiro lugar, seria preciso considerar a complexa questão da sexualidade na antiguidade. Afinal de contas, uma categoria como 'sentimentos homossexuais' parece consideravelmente anacrônica para tratar do que é expresso pelofr. 31, uma vez que a própria construção da oposição binária entre heterossexualidade e homossexualidade é bastante recente em termos históricos. Com relação a isso, os estudos de Michel Foucault (1976) e Judith Butler (2017) (orig. de 1990) não deixam muita margem para dúvida. Entre nós, Ragusa (2005, p. 42) manifesta seu descontentamento com esse tipo de leitura contemporânea, ao dizer que Safo de Lesbos se transformou em objeto predileto dos gay studies e dos women studies a partir de inferências extraídas de seus poemas com as quais, em boa parte, foi construída o que ela chama de uma "biografia ficcionalizada" (RAGUSA, 2005, p. 42). A estudiosa destaca ainda a necessidade de extremo cuidado na interpretação dessa poesia, enfatizando a necessidade de se alcançar o maior distanciamento possível de certas leituras modernas da lírica grega a fim de se entender sua especificidade antiga (RAGUSA, 2005). Assim sendo, é preciso cuidado quando se fala da expressão de sentimentos homoafetivos na poesia de Safo, uma vez que eles tinham curso no âmbito de instituições sociais muito diferentes das que conhecemos hoje. De toda forma, acreditamos que esse poema realmente não representa os sintomas de um ataque de ciúmes, mas sim as manifestações exteriores de uma paixão erótica. A fim de defendermos essa interpretação, contudo, será preciso enfrentar uma série de argumentos de ordem gramatical, desenvolvidos sobretudo a partir da conjugação de alguns dos verbos empregados pelo poema.

Os verbos isdánei [senta-se] e ypakoúei [escuta] - listados como ações praticadas pelo homem da primeira estrofe - encontram-se no presente do indicativo, enquanto o verbo $i d \bar{o}$ [vejo] - praticado pela persona do poema - está no aoristo subjuntivo. Isso talvez pudesse sugerir a virtualidade das considerações acerca dos sintomas patológicos da persona, em detrimento de uma constatação fática daquilo que se passaria entre 'aquele homem' e a garota que fala e ri próximo a ele, ainda que tal evento tenha acontecido uma única vez. Contudo, o presente do indicativo pode ter valor geral e, dessa maneira, adquirir um sentido de consideração hipotética, não apenas de uma constatação fática; como indica o breve estudo de William Annis (2004), Safo pode muito bem estar iniciando o poema com uma afirmação de caráter geral. Nesse sentido, poderíamos inclusive aceitar a sugestão de que o aspecto durativo do presente estaria empregado para se contrapor à brevidade da ação que a persona do poema suporta (já que o verbo praticado por ela está conjugado no aoristo):

\begin{abstract}
Além disso, parece existir um outro contraste pretendido: aquele entre o aspecto durativo do

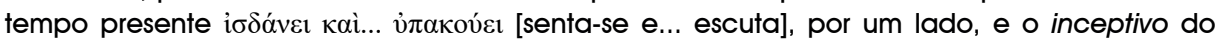

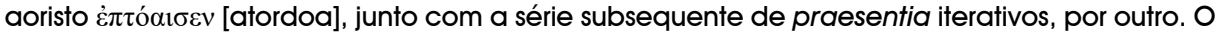
homem é forte o bastante para permanecer sentado, escutando (e presumivelmente olhando para a garota também), enquanto a própria Safo mostra-se incapaz de suportar a presença da garota por um momento, mas é nocauteada ao vê-la pela primeira vez (cf. $7 \beta \rho o ́ \chi \varepsilon(\alpha)$ [breve],

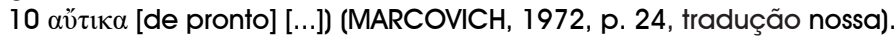

Essa sugestão oferece uma boa explicação para o questionamento acerca do arranjo verbal expresso nesses versos, além de dirimir as dificuldades com relação à presença 'daquele homem' na primeira estrofe e à sua desaparição nas estrofes seguintes. A função dessa figura é apenas a de contrastar a imperturbabilidade de alguém que não se deixa afetar por determinada beleza - daí o seu epíteto como ísos théoisin [semelhante aos deuses] - com os sintomas de alguém que é totalmente arrebatado pela influência da paixão por tal beleza.

Essa leitura coloca 'aquele homem' em seu devido lugar, propondo uma interpretação que nem ignora a sua menção na primeira estrofe, nem a supervaloriza (como nas propostas que fariam dele a razão principal da existência do poema). É certo que os estudos de sexualidade e gênero desanuviaram consideravelmente as interpretações de muitos dos poemas de Safo - e de outros poetas - das suposições falocêntricas características de uma cultura eminentemente masculina. Nesse sentido, é possível encontrar uma crítica contundente das abordagens sexistas que, por exemplo, Denys Page e George Devereux haviam oferecido em suas leituras do fr. 31 
de Safo no trabalho de Mary Lefkowitz (1996). No caso do poema em questão, essas suposições pregavam que a figura 'daquele homem' seria real, seja a de um noivo ou a de um competidor pelo amor da garota, e sua presença fática deveria coordenar a interpretação do restante do texto (ainda que ele só aparecesse em menos de um quarto do número total de versos conservados do poema). O pronome relativo indeterminado óttis [aquele qualquer], contudo, que tem ecos da cena em que Nausícaa vê Odisseu pela primeira vez na Odisseia (6.158-61), daria uma dica clara acerca da indeterminação de caráter hipotético acerca de tal 'homem':

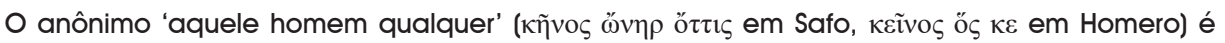
um clichê, não um ator na cena imaginada. Interpretações que focam em 'aquele qualquer (masculino)' como o noivo (ou pretendente ou amigo) que está na verdade presente e ocupando a atenção do público não notam a estratégia de persuasão que informa o poema e, fazendo isso, revelam suas próprias premissas androcêntricas. Retratando 'o homem' como uma pessoa concreta, central para a cena e divino em poder, tais interpretações confundem a figura de discurso como uma constatação literal e então acrescentam o peso de seus próprios valores pró-masculinos à consciência de Safo centrada na mulher (Jack WINKLER, 1996, p. 99 , tradução nossa).

Ainda que a interpretação do poema não esteja encerrada, é certo que tendemos preponderantemente a interpretar tais versos como a descrição hiperbólica de sintomas virtuais de uma paixão erótica que afetaria a persona se ela fosse posta à prova da mesma forma que 'aquele homem'. É preciso notar que, além dos argumentos e paralelos já traçados para se defender essa ideia, o tópos retórico em que a ataraxia de alguém não afetado pela beleza da pessoa amada é comparada à afecção hiperbólica daquele que ama adquiriu uma importância considerável entre poetas posteriores quando cantam o amor. Tal como indicado por Race (1983), exemplos de passagens que retomam e desenvolvem esse tópos estariam presentes nas obras de Apolônio de Rodes (3.744), Meleagro (Antologia Palatina 12.127) e Virgílio (Bucólicas 2.9-13, 2.66-68 e Eneida 4.522), por exemplo. O contraste entre a calma exterior e as tormentas da paixão sentida no interior da persona poética é exemplarmente retomado no seguinte trecho de um dos Idílios de Teócrito:

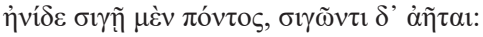

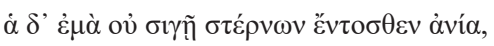

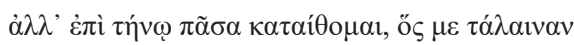

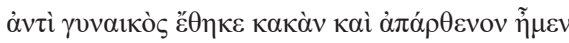

(TEÓCRITO, Idílios 2.38-41).

Olha, o mar se cala, também se calam os ventos,

dentro do peito, porém, não se cala a minha aflição,

mas por ele eu ardo inteirinha, e a mim, desgraçada,

ele me fez, não esposa, senão ex-donzela somente

(Trad. Érico Nogueira, 2012).

Outro argumento importante, embora não tenha recebido uma formulação explícita anterior (pelo menos dentre os estudos consultados), poderia ser pensado e desdobrado a partir de uma constatação comum entre estudiosos do poema: um dos sintomas patológicos mais perigosos para um/a poeta de tradição oral é justamente o silêncio. Sabemos que Safo cantava suas composições poéticas com acompanhamento de um instrumento de cordas, geralmente uma lira ou um bárbito, em contextos de performance às vezes públicos às vezes privados, mas sempre com a presença de alguns participantes (John HERINGTON, 1985; RAGUSA, 2013). Para alguém cuja obra só pôde ser transmitida por meio de inúmeras performances e re-performances orais ao longo dos séculos, no âmbito da cultura musical grega antiga, o silêncio apresentava o mais terrível dos riscos. Do silêncio, advinham a morte da palavra e o esquecimento do nome. Do silêncio, advinha o fim da própria canção. A persona poética do fr. 31 tem plena consciência desses riscos do silêncio e manifesta essa consciência com plena força no verso 9, ao afirmar: "mas toda a língua se quebra". No original grego, há a presença inclusive de um problema métrico na palavra éage [se quebra] (justamente por isso destacada pelos obeliscos), podendo haver um

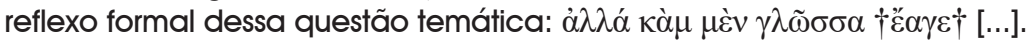


Nesse sentido, notando o eco do vocabulário típico das batalhas homéricas na descrição dos sintomas relatados pela persona do poema, Dolores O'Higgins (1990) sugere o seguinte:

Também para a persona de Safo 31, o campo de batalha do Amor parece tenso, instável e letal, com a ameaça adicional de oblívio, já que a ameaçada 'combatente' do amor é também uma cantora. A morte dessa 'combatente', longe de oferecer uma glória custosa para a heroína a partir da poeta ou da tradição poética, vai necessariamente silenciar a cantora (O'HIGGINS, 1990, p. 163, tradução nossa).

O que a estudiosa deixa de comentar, contudo, é que se Safo consegue resistir e lançar um poema que a perpetua para além de todo e qualquer silêncio é porque os sintomas patológicos descritos por ela são apenas virtuais. Ainda que possamos admitir a sugestão de que o emprego do termo éage reproduza uma perturbação na voz da poeta (por meio do hiato que parece intencionalmente criado), é certo que a descrição hiperbólica dessa afecção profunda é meramente 'fantasiosa'. Do contrário, a potência com que as palavras desse poema são articuladas e emitidas contradiria a profundidade da afecção sugerida, diminuindo assim o seu impacto poético.

Assim sendo, o caráter 'virtual' das considerações esboçadas nesses versos - caráter que se deve em primeiro lugar à escolha dos modos verbais - é reforçado pelo emprego do verbo phaínomai [pareço] no interior de uma estrutura que sugere uma composição em anel: esse mesmo verbo aparece conjugado na terceira pessoa do singular no primeiro verso, phainetai [parece], ligado à figura 'daquele homem', e é retomado na primeira pessoa do singular no v. 16, phaínomai [pareço], ligado portanto à figura da persona poética. Acompanhando a evolução de sentido por que passa o radical desse verbo nos séculos seguintes, poderíamos sugerir que todas as considerações elaboradas ao longo desse poema - desde a presença 'daquele homem' até a manifestação dos sintomas patológicos junto à persona - seriam produto da phantasía dessa poeta, conforme a sugestão elaborada por Lefkowitz (1996).

O recurso à linguagem poética tradicional poderia ser tido ainda por outro indicador de que. mais do que relatar uma anedota, a poeta se vale do momento de performance, na qual o emprego de determinados tópoi poéticos seria imprescindível para exprimir uma perspectiva acerca do mundo, da tradição e de seu próprio posicionamento em meio a isso. Por um lado, o caráter comunal das performances dos poetas arcaicos coordena o emprego de determinados vocábulos e motivos tradicionais, por outro, as especificidades do olhar de Safo revelam-se na forma sutil por que ela subverte esses lugares-comuns da tradição poética (WINKLER, 1996).

Assim sendo, muitos ecos homéricos, por exemplo, já tinham sido notados no fr. 31 de Safo por Marcovich (1972), que mencionava a possibilidade de que os sintomas relatados ao longo de suas estrofes não fossem mera descrição da realidade, mas a construção poética de uma imagem por meio do emprego da linguagem homérica mais comum à tradição de poesia grega arcaica. Também nessa tentativa de compreender os limites entre a linguagem tradicional e aquilo que há de peculiar à poesia sáfica, Charles Segal (1996) propõe as seguintes considerações:

As raízes da poesia de Safo, em outras palavras, podem estar não apenas na intensidade de suas próprias experiências eróticas (e eu não vejo razão para negar sua realidade), mas também em sua capacidade para intuir, para viver imaginativamente e para recriar poeticamente as experiências emocionais que eram da maior importância para o círculo ao qual pertencia. A linguagem formalizada do amor, então, não apenas expressa emotividade privada, mas constitui o meio de se generalizar a experiência erótica e traduzir o pessoal e o privado numa forma visível e comunicável (SEGAL, 1996, p. 71, tradução nossa).

A posição dúbia de Safo - inserida no seio de uma tradição falocêntrica, ainda que originária de uma cultura alternativa, da qual tinha plena e zelosa consciência - é o que torna sua poesia tão rica e multifacetada. As considerações propostas por Winkler (1996) sobre a complexidade das 'linguagens de minoria' numa sociedade em que a 'linguagem da maioria' as exclui - tal como ele explicita a partir da leitura de alguns poemas de Safo, nos quais emerge uma voz feminina normalmente marginalizada por uma tradição eminentemente masculina demonstram o caráter riquíssimo que essas linguagens podem assumir em suas alusões, menções veladas e subversões em múltiplas camadas de sentido. Para o caso de culturas androcêntricas, como ocorre com a cultura helênica, o estudioso afirma o seguinte:

Porque homens definem e exibem sua linguagem e costumes como a cultura e segregam a linguagem e costumes das mulheres como uma subcultura, inacessível para e protegida de homens extrafamiliares, mulheres estão em condições de conhecer duas culturas enquanto homens conhecem apenas uma. Do ponto de vista da consciência, devemos diagramar 0 círculo da literatura feminina como um mais largo, que inclui a literatura masculina como uma fase ou compartimento do conhecimento cultural feminino. Mulheres numa sociedade proeminentemente masculina são então como uma minoria linguística numa cultura cujas ações públicas são todas conduzidas na língua da maioria. Para participar mesmo passivamente na arena pública, a minoria precisa ser bilíngue; a maioria não sente necessidade alguma 
de aprender a língua da minoria. A consciência de Safo, então, é necessariamente uma consciência dupla, sua participação na tradição literária pública sempre contém uma alienação inevitável (WINKLER, 1996, p. 95, tradução nossa).

A leitura da poesia de Safo a partir da tomada de consciência de sua inserção num diálogo - o qual poderíamos compreender como profundamente dialético e tenso - com a tradição homérica permite um refinamento em nossa interpretação dos versos cantados e executados por essa poeta. A complexidade de sua produção poética revela-se na forma caracteristicamente ambivalente de suas palavras, aptas a serem lidas tanto a partir de sua camada superficial de sentido quanto a partir dos jogos mais profundos e complexos com a tradição poética. No caso das alusões épicas presentes no fr. 31, o mesmo estudioso afirma o seguinte:

Executando esse experimento de ler os poemas de Safo como se expressassem, em parte, seus pensamentos enquanto lê Homero, sua consciência do mundo público dos homens, eu a considero estar naturalmente atraída pelo caráter de Nausícaa, cuja antecipação romântica (Odisseia 6.27) e delicada sensibilidade à inatingibilidade do poderoso estrangeiro (244f., 27684) estão entre as mais bem-sucedidas apresentações da mente feminina na literatura grega masculina. Safo vê a si própria tanto como Odisseu, admirando a moça de aparência de ninfa, como Nausícaa, prezando suas próprias emoções complexas (WINKLER, 1996, p. 101, tradução nossa).

A riqueza desse tipo de leitura revela o avanço de estudos que permitem ler e interpretar textos à luz de novas considerações, em parte mais livres (e, quando não, ao menos mais conscientes) de pressuposições que deformam textos potencialmente subversivos ao abordálos e domesticá-los a partir da perspectiva do grupo dominante numa dada sociedade. No caso de Safo, essas abordagens tradicionais tendem a rechaçar os aspectos mais radicais de sua poética, tais como a releitura profunda que ela leva a cabo de toda a tradição épica, a contestação da subalternidade feminina e o recalque da sexualidade e do prazer da mulher. No estudo que dedica à linguagem amatória de Safo, Giuliana Lanata (1996) defende que as seleções feitas pela poeta no âmbito do patrimônio lexical da poesia épica, como os novos meios linguísticos com os quais ela dava expressão a um mundo diverso do mundo épico, estavam destinadas, por sua vez, a se consolidar como tradicionais. Que tais dimensões da poética sáfica comecem a ser ressaltadas em algumas das leituras mais recentes de sua obra é um importante indicativo de que os olhos da recepção aos poucos são iluminados por feixes que the permitem ver facetas encobertas por séculos de violência, silêncio e revolta velada.

Em que pesem esses avanços, contudo, a questão está longe de uma decisão definitiva. Em texto publicado recentemente, o helenista brasileiro André Malta (2018) retomou o posicionamento dos que defendem a presença do ciúme como o principal motivo do sofrimento descrito pela persona poética do fr. 31 de Safo. Segundo o estudioso:

É possível dizer, [...] valendo-se de uma analogia com o cinema, que a câmera enquadra de início a figura masculina ( $3^{a}$. pessoa), depois a feminina à sua frente $\left(2^{a}\right.$. pessoa), e em seguida se volta para si mesma ( ${ }^{a}$. pessoa), para analisar suas reações diante desse quadro, ou dessa mulher, que perturba. Muitos já notaram que é uma situação de exclusão ou rejeição [...]: o homem se iguala aos deuses porque está tranquilo diante da jovem, com acesso à doçura da sua fala e à sedução do seu riso, enquanto o 'eu' que os observa e diz o poema está, senão física, ao menos 'espiritualmente' distante da dupla. Insinua-se assim, mas sem se confirmar de modo explícito, o sentimento do ciúme ou, para usar a expressão popular, da dor de cotovelo, quando não se tem o amor correspondido ou se é preterido. A proximidade do casal e seu entrosamento têm relação direta com a dor de quem os vê (MALTA, 2018, p. 100).

Como percebemos, o helenista volta aqui a dar ênfase exagerada à figura masculina em sua interpretação geral do poema - embora ela seja mencionada apenas na primeira estrofe, desaparecendo do restante dos versos - e prefere compreender a descrição dos sintomas patológicos sofridos pela persona poética como fruto de uma "dor de cotovelo" (MALTA, 2018, p. 100). Acreditamos que os problemas graves desse tipo de interpretação, bem como um breve repertório com alguns dos principais nomes que a propuseram e a defenderam ao longo da história, tenham sido convenientemente expostos no início deste texto; assim sendo, o juízo sobre o que se encontra em jogo no fr. 31 de Safo cabe apenas a quem ora nos lê. Os argumentos fundamentais para se posicionar com relação à complexa problemática em torno à leitura desse poema foram evidenciados a partir de uma análise e exposição atentas de todas as propostas consultadas.

Curiosamente, no mesmo ano em que saiu o texto de Malta (2018), foi dada mais uma vez a lume uma recente tradução do célebre fragmento. Assinada por Tereza Virgínia Ribeiro Barbosa (2018), essa tradução - que saíra pela primeira vez no ano anterior (BARBOSA, 2017) - vinha acompanhada de uma breve análise de outras propostas e versões do poema para línguas modernas. Ainda que tenhamos ressalvas com relação a alguns pontos da proposta, gostaríamos de encerrar aqui com a menção integral a essa tradução, uma vez que sua autora 
busca enfatizar a dimensão sensorial e sensual presente no poema grego antigo (BARBOSA, 2018 , p. 237). Com isso, encerramos nosso artigo oferecendo mais uma vez o espaço necessário para que a voz apaixonada de Safo volte a ressoar entre nós:

\author{
Fulgura como os deuses um que me \\ surge, varão, que, diante de ti, \\ se assenta, e, junto, dócil a que \\ fala e ri ardente \\ escuta, e isso, de pronto, \\ me desatina no peito o coração! \\ Pois, no que te vejo, súbito eu nada \\ mais sei falar, \\ assim, logo se me engrola a língua; sutil, \\ num átimo, um fogo dispara sob a pele \\ e, nas vistas, nada diviso; os ouvi- \\ dos trovoam, \\ daí, suor me poreja de alto a baixo, então, \\ tremuras me tomam toda, orvalhada fico, mais \\ que a relva, com pouco lassa, morta \\ figuro estar \\ e, toda impudente, baldia já... \\ (SAFO, fr. 31, trad. Tereza Virgínia Ribeiro Barbosa).
}

\title{
Referências
}

ANNIS, William. "Sappho: Fragment 31". Aoidoi.org, 2004. Disponível em http://www.aoidoi.org/ poets/sappho/sappho-31.pdf. Acesso em 02/11/2015.

AULOTTE, Robert. "Sur quelques traductions d'une ode de Sappho au XVle siècle". Bulletin de l'Association Guillaume Budé, Paris, n. 17, p. 107-122, dez. 1958. Disponível em https://www. persee.fr/doc/bude_1247-6862_1958_num_17_4_4178. Acesso em 26/12/2019.

BARBOSA, Tereza Virgínia Ribeiro. "Safo 31 Voigt: mil traduções e mais uma". Revista da Anpoll, Florianópolis, v. 1, n. 44, p. 231-245, jan./abr. 2018.

BARBOSA, Tereza Virgínia Ribeiro. "Safo 31 Voigt: Uma tradução". Contextura, Belo Horizonte, n. 10, p. 07-15, ago. 2017.

BUTLER, Judith. Problemas de gênero: feminismo e subversão da identidade. Tradução de Renato Aguiar. 13. ed. Rio de Janeiro: Civilização Brasileira, 2017.

DACIER, Madame. Les poesies d'Anacreon et de Sapho traduites de Grec en Français, avec des remarques par Madame Dacier. Nouvelle edition augmentée des notes latines de Mr. Le Fèvre. Amsterdam: Paul Marret, 1699. 
FABRE-SERRIS, Jacqueline. "Anne Dacier (1681), Renée Vivien (1903): Or What Does It Mean for a Woman to Translate Sappho?". In: WYLES, Rosie; HALL, Edith (Ed.). Women Classical Scholars: Unsealing the Fountain from the Renaissance to Jacqueline de Romilly. Oxford: Oxford University Press, 2016. p. 78-102.

FOUCAULT, Michel. Histoire de la sexualité. Paris: Gallimard, 1976.

HALLETT, Judith P.. "Feminist Theory, Historical Periods, Literary Canons, and the Study of GrecoRoman Antiquity". In: RABINOWITZ, Nancy Sorkin; RICHLIN, Amy (Ed.). Feminist theory and the classics. New York; London: Routledge, 1993. p. 53-73.

HALLETT, Judith P.. "Sappho and Her Social Context: Sense and Sensuality". In: GREENE, Ellen (Ed.). Reading Sappho: Contemporary Approaches. Berkeley: University of California Press, 1996. p. 125-142.

HERINGTON, John. Poetry into drama. Early tragedy and the Greek poetic tradition. Berkeley: University of California Press, 1985.

LANATA, Giuliana. “Sappho's Amatory Language”. In: GREENE, Ellen (Ed.). Reading Sappho: Contemporary Approaches. Berkeley: University of California Press, 1996. p. 11-25.

LEFKOWITZ, Mary. "Critical Stereotypes and the Poetry of Sappho". In: GREENE, Ellen (Ed.). Reading Sappho: Contemporary Approaches. Berkeley: University of California Press, 1996. p. 26-34.

MALTA, André. "Re-visão do amor em Safo ou Safo para além de Safo". Anais de Filosofia Clássica, v. 12, n. 23, p. 96-106, 2018.

MARCOVICH, Miroslav. "Sappho, Fr. 31 : Anxiety Attack or Love Declaration?". Classical Quarterly, Cambridge, n. 66, p. 19-32, May 1972.

MCEVILLEY, Thomas. "Sappho, Fragment Thirty One: The Face behind the Mask". Phoenix, Toronto, n. 32, p. 01-18, Mar./May 1978.

NOGUEIRA, Érico. Verdade, contenda e poesia nos Idílios de Teócrito. 2012. Doutorado (Programa de Pós-Graduação em Letras Clássicas) - Faculdade de Filosofia, Letras e Ciências Humanas da Universidade de São Paulo, São Paulo, SP, Brasil.

O'HIGGINS, Dolores. "Sappho's Splintered Tongue: Silence in Sappho 31 and Catullus 51". American Journal of Philology, Baltimore, n. 111, p. 156-167, June/Aug. 1990.

RACE, William H. “'That Man' in Sappho fr. 31 L-P”. Classical Antiquity, v. 2, n. 1, p. 92-101, Apr. 1983.

RAGUSA, Giuliana. Fragmentos de uma deusa: A representação de Afrodite na lírica de Safo. Campinas: Editora da UNICAMP, 2005.

RAGUSA, Giuliana. Lira grega: antologia de poesia arcaica. Organização e tradução de Giuliana Ragusa. São Paulo: Hedra, 2013.

SEGAL, Charles. "Eros and Incantation: Sappho and Oral Poetry". In: GREENE, Ellen (Ed.). Reading Sappho: Contemporary Approaches. Berkeley: University of California Press, 1996. p. 58-78.

SNELL, Bruno. A cultura grega e as origens do pensamento europeu. Tradução de Pérola de Carvalho. São Paulo: Perspectiva, 2012.

VIVIEN, Renée. Sapho. Traduction nouvelle avec le texte grec. Paris: Alphonse Lemerre, 1903.

WILAMOWITZ-MOELLENDORFF, Ulrich von. Sappho und Simonides: Untersuchungen über griechische Lyriker. Berlin: Weidmannsche Buchhandlung, 1913.

WINKLER, Jack. "Gardens of Nymphs: Public and Private in Sappho's Lyrics". In: GREENE, Ellen (Ed.). Reading Sappho: Contemporary Approaches. Berkeley: University of California Press, 1996. p. 89-112.

WOOLF, Virginia. A room of one's own. Edited by David Bradshaw and Stuart N. Clarke. West Sussex: John Wiley \& Sons Ltd, 2015. 
Sara Camila Barbosa dos Anjos (scbanjos@ufmg.br; scbanjos@gmail.com) é estudante de graduação em Letras Clássicas na Universidade Federal de Minas Gerais (UFMG), estagiária no projeto de extensão Contos de mitologia, com participações como atriz em apresentações do grupo Trupersa (2019). Tem interesse pelas áreas de literatura, teatro e estudos queer e de gênero.

Rafael Guimaraes Tavares da Silva (rafadaemon@ufmg.br; gtsilva.rafa@gmail.com) é estudante de Língua e Literatura Clássicas (Grego Antigo), doutorando no PÓS-LIT da UFMG, com interesses que vão da Filosofia e da História (Antigas e Contemporâneas) à Teoria da Literatura, além de teoria e prática da Tradução e da Educação. Trabalha diversos temas relacionados à literatura e ao teatro, em abordagens marcadas principalmente pelo viés da desconstrução e do pós-estruturalismo.

\section{COMO CITAR ESTE ARTICO DE ACORDO COM AS NORMAS DA REVISTA}

ANJOS, Sara Camila Barbosa dos; SILVA, Rafael Guimaraes Tavares da. "Violência, silêncio e revolta velada nas leituras de Safo (fr. 31 Voigt)". Revista Estudos Feministas, Florianópolis, v. 29, n. 3, e71408, 2021.

\section{CONTRIBUIÇĀO DE AUTORIA}

Os autores contribuíram igualmente.

\section{FINANCIAMENTO}

Este trabalho foi realizado com apoio da Coordenação de Aperfeiçoamento de Pessoal de Nível Superior Brasil (CAPES) - Código de Financiamento 001

\section{CONSENTIMENTO DE USO DE IMAGEM}

Não se aplica.

\section{APROVAÇĀO DE COMITÊ DE ÉTICA EM PESQUISA}

Não se aplica.

\section{CONFLITO DE INTERESSES}

Não se aplica.

\section{LICENÇA DE USO}

Este artigo está licenciado sob a Licença Creative Commons CC-BY 4.0 International. Com essa licença você pode compartilhar, adaptar, criar para qualquer fim, desde que atribua a autoria da obra.

\section{HISTÓRICO}

